"This document is the Accepted Manuscript version of a Published Work that appeared in final form in Org. Lett. 2017, 19, 6388-6391, copyright (C) American Chemical Society after peer review and technical editing by the publisher. To access the final edited and published work see DOI: 10.1021/acs.orglett.7b03247. This article may be used for non-commercial purposes in accordance with the ACS guidelines published at http://pubs.acs.org/page/policy/articlesonrequest/index.html]." 


\title{
Pd-Catalyzed Enantio- and Regioselective Formation of Allylic Aryl Ethers
}

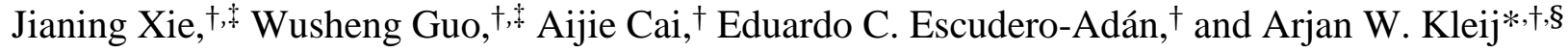

${ }^{\dagger}$ Institute of Chemical Research of Catalonia (ICIQ), the Barcelona Institute of Science and Technology, Av. Països Catalans 16, 43007 - Tarragona, Spain

${ }^{\S}$ Catalan Institute of Research and Advanced Studies (ICREA), Pg. Lluís Companys 23, 08010 - Barcelona, Spain

Supporting Information Placeholder
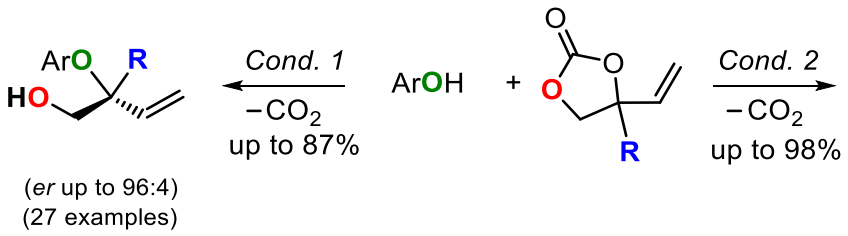

up to $87 \%$

(27 examples)

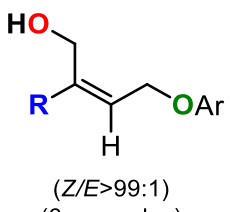

(6 examples)

ABSTRACT: A general methodology for the synthesis of enantioenriched tertiary allylic aryl ethers through Pd-catalyzed decarboxylative reactions of vinyl cyclic carbonates and phenols is presented. Switching of the regioselectivity toward the formation of linear products by a judicious choice of the ligand is also reported.

Chiral tertiary allylic aryl ethers are important building blocks in the synthesis of natural products and biologically active compounds such as Ustiloxin D, Vitamin E and products known as peroxisome proliferator-activated receptor $\gamma(\operatorname{PPAR} \gamma)$ modulators (Scheme 1). ${ }^{1-3}$ The asymmetric allylic substitution with phenols as nucleophiles represents the most versatile and straightforward method toward the synthesis of sterically hindered tertiary allylic aryl ethers. The synthesis of enantioenriched secondary allylic aryl ethers through phenol nucleophilic substitution has been well-established. ${ }^{4}$ However, the regioselective synthesis of sterically congested tertiary allylic aryl ethers featuring a tertiary carbon stereocenter through allylic substitution is still a huge challenge.$^{5-7}$ Seminal work from Trost illustrated the use of an intramolecular strategy $\mathrm{y}^{2 \mathrm{a}-\mathrm{d}}$ to give rise to the desired aryl ethers, avoiding the formation of regioisomers, though only focused on the preparation of chromanes and with limitations in substitution diversity (Scheme 2, eq 1).

Scheme 1. Representatives of Natural Products or Pharmaceuticals Featuring Chiral Tertiary Aryl Ether Fragments

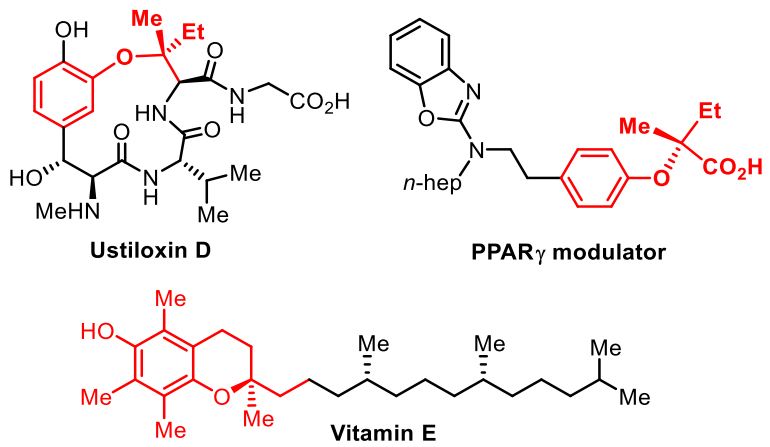

Scheme 2. Pd-Catalyzed Asymmetric Synthesis of Allylic Scaffolds Featuring Tertiary Carbon Stereocenters

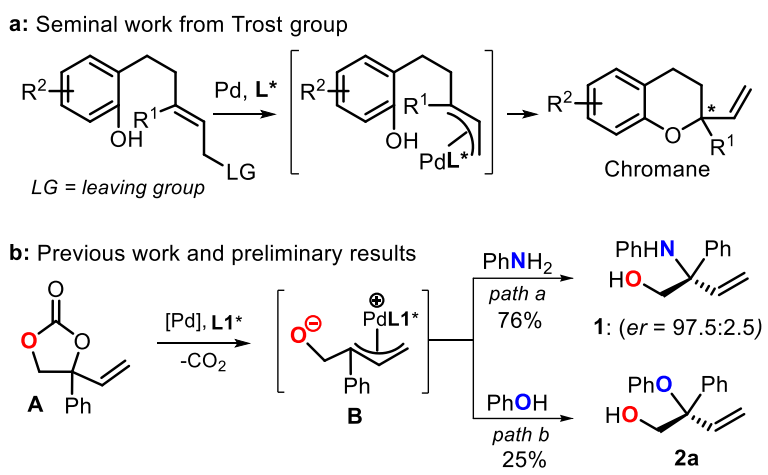

c: Working hypothesis toward tertiary allylic aryl ethers

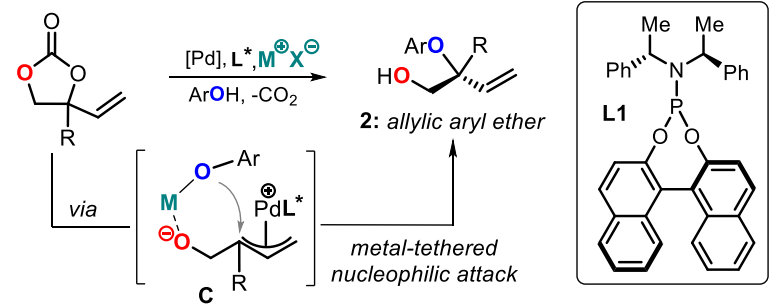

Transition-metal-catalyzed decarboxylative transformation of vinyl cyclic carbonates has proven to be a versatile method toward the formation of various allylic scaffolds. ${ }^{8,9}$ Our group recently reported the first regio- and enantioselective synthesis of $\alpha, \alpha$-disubstituted allylic $N$-arylamines based on a Pd-catalyzed

Table 1. Selected Data for the Optimization of the Reaction Conditions towards the Enantioenriched Aryl Ether 2a ${ }^{a}$ 


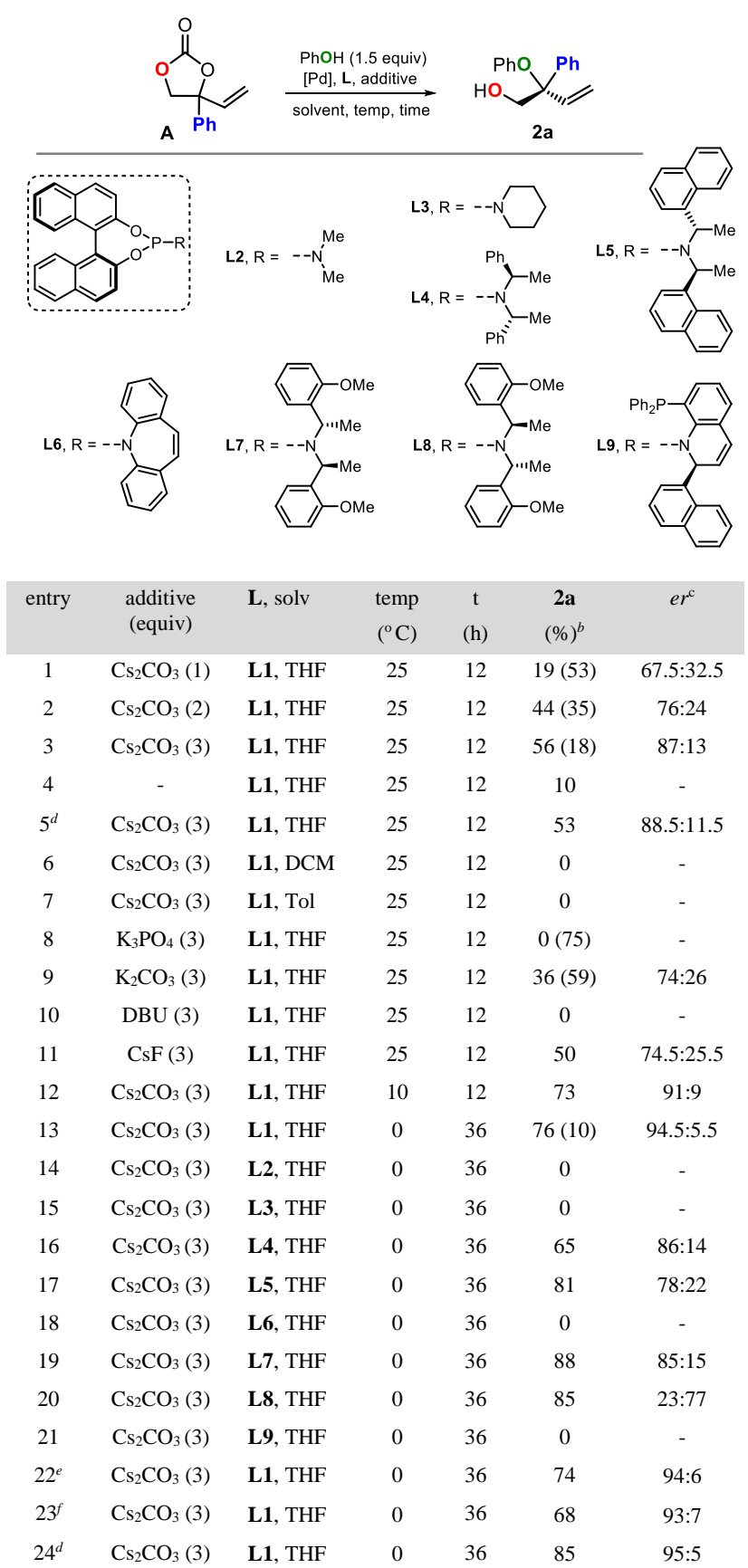

${ }^{a}$ Reaction conditions unless otherwise stated: carbonate $\mathbf{A}(0.20 \mathrm{mmol}, 1$ equiv), phenol (1.5 equiv), $\mathrm{Pd}_{2}(\mathrm{dba})_{3} \cdot \mathrm{CHCl}_{3}(2 \mathrm{~mol} \%)$, ligand $\mathbf{L}(8 \mathrm{~mol} \%)$, THF $(0.20 \mathrm{~mL})$, open to air. ${ }^{b}$ Isolated yield of $\mathbf{2 a}$, in brackets the NMR yield of the linear product. ${ }^{c}$ Determined by HPLC. ${ }^{d}$ Using $0.30 \mathrm{~mL}$ of THF. ${ }^{e} \mathrm{Phenol}$ (1.2 equiv). ${ }^{f} \mathrm{Pd}_{2}\left(\mathrm{dba}_{3} \cdot{ }^{\circ} \mathrm{CHCl}_{3}(1.25 \mathrm{~mol} \%)\right.$, ligand $\mathbf{L 1}(5 \mathrm{~mol} \%)$.

conversion of cyclic carbonate $\mathbf{A}$ through a zwitterionic intermediate $\mathbf{B}$ in presence of phosphoramidite ligand L1 (Scheme 2, eq 2, path a, L1 inset in Scheme 2). ${ }^{10} \mathrm{We}$ expected that the synthesis of enantioenriched tertiary aryl ether $\mathbf{2 a}$ would be feasible by changing the nucleophile from aniline to phenol under the similar reaction conditions; thus, the reaction of carbonate A and phenol was performed, but unfortunately only $25 \%$ of the aryl ether 2a was isolated. Notably, substantial amount of undesired linear product (Scheme 2, eq 2, path b) was formed. Considering the strong interaction between oxygen and metal cationic species, ${ }^{11}$ we envisaged that, in the presence of a phosphoramidite ligand, the presence of suitable metal cations would help to direct the nucleophilic attack toward the internal carbon center of the Pd-allyl intermediate $\mathbf{C}$ rather than the less hindered terminal one (Scheme 2, eq 3). ${ }^{12}$

\section{Scheme 3. The Scope in Phenols to Produce Aryl Ethers $2^{a}$}

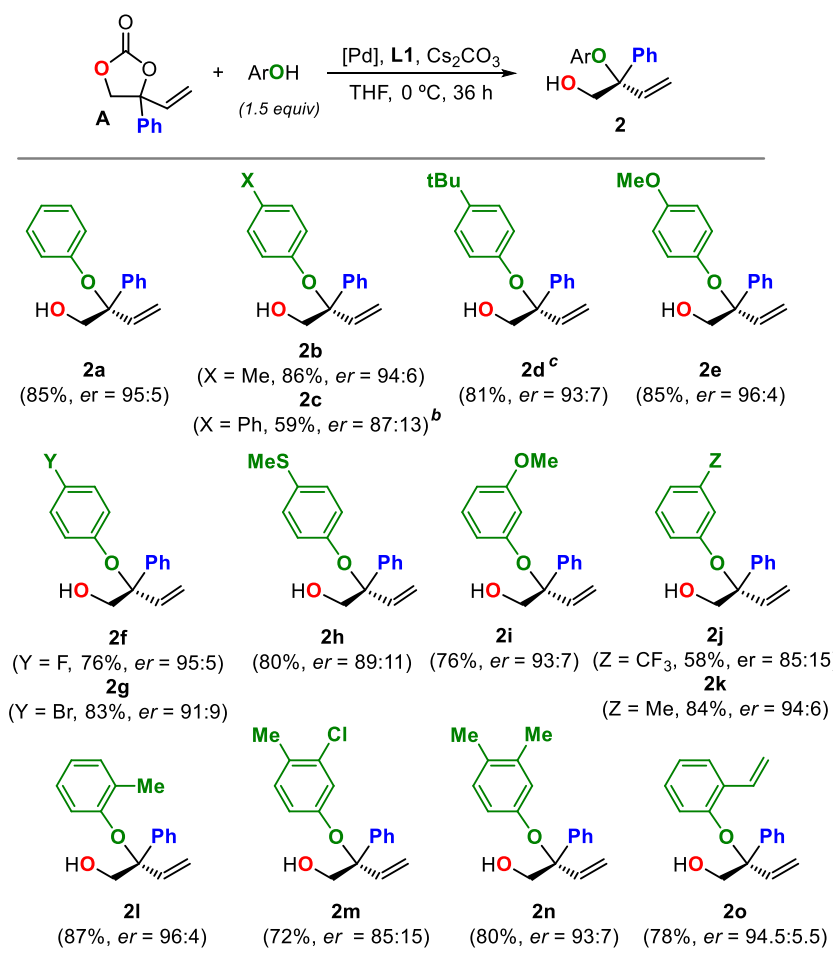

${ }^{a}$ Reaction conditions unless stated otherwise: carbonate A $(0.20$ $\mathrm{mmol})$, phenol partner (1.5 equiv), THF $(0.30 \mathrm{~mL})$, $\mathrm{Pd}_{2}(\mathrm{dba})_{3} \cdot \mathrm{CHCl}_{3}(2 \mathrm{~mol} \%), \mathbf{L 1}(8 \mathrm{~mol} \%), \mathrm{Cs}_{2} \mathrm{CO}_{3}$ ( 3 equiv), $0{ }^{\circ} \mathrm{C}$, $36 \mathrm{~h}$. Isolated yields are reported. ${ }^{b} 60 \mathrm{~h} .{ }^{c} 45 \mathrm{~h}$.

In order to check our working hypothesis, we chose the reaction of cyclic carbonate $\mathbf{A}$ and phenol as a model reaction (Table 1). $\mathrm{Cs}_{2} \mathrm{CO}_{3}$ was first examined as the metal cation source with the use of $\mathbf{L 1}$ (inset in Scheme 2). ${ }^{13} \mathrm{We}$ were pleased to find that the addition of three equivalents of $\mathrm{Cs}_{2} \mathrm{CO}_{3}$ led to appreciable product formation (2a, 56\% yield) with an er of 87:13 (Table 1, entries 1-3). The control reaction in the absence of $\mathrm{Cs}_{2} \mathrm{CO}_{3}$ only gave rise to $10 \%$ of product, suggesting the crucial role of the Cs salt (Table 1, entry 4). The reactions performed at lower concentration or the use of other solvents/potassium salts ${ }^{13}$ did not improve the results significantly (Table 1, entries 5-9). No reaction was observed in the presence of DBU suggesting that basicity is probably not a key parameter (Table 1, entry 10). The use of CsF (Table 1, entry 11) showed a similar outcome ( $c f$., entry 3 ) further confirming the key role of the Cs cation in this reaction. ${ }^{13}$ Lowering the reaction temperature to 0 ${ }^{\circ} \mathrm{C}$ significantly improved the yield $(76 \%)$ and enantioselectivity (Table 1 , entries $12-13$, er $=94.5: 5.5$ ) despite the requirement of longer reaction times. The attempt to improve the enantioselectivity with other phosphoramidite ligands L2-L9 was not successful (Table 1, entries 14-21). A lower amount of phenol (Table 1, entry 22) or catalyst loading (Table 1, entry 23) gave slightly inferior results. Performing the reaction under diluted conditions gave $\mathbf{2 a}$ in $85 \%$ yield with an er of 95:5 (Table 
1, entry 24), and these optimized reaction conditions were then applied to investigate the scope of these allylic etherifications.

Scheme 4. The Scope in Cyclic Carbonates to Produce Allylic Aryl Ethers $3^{a}$
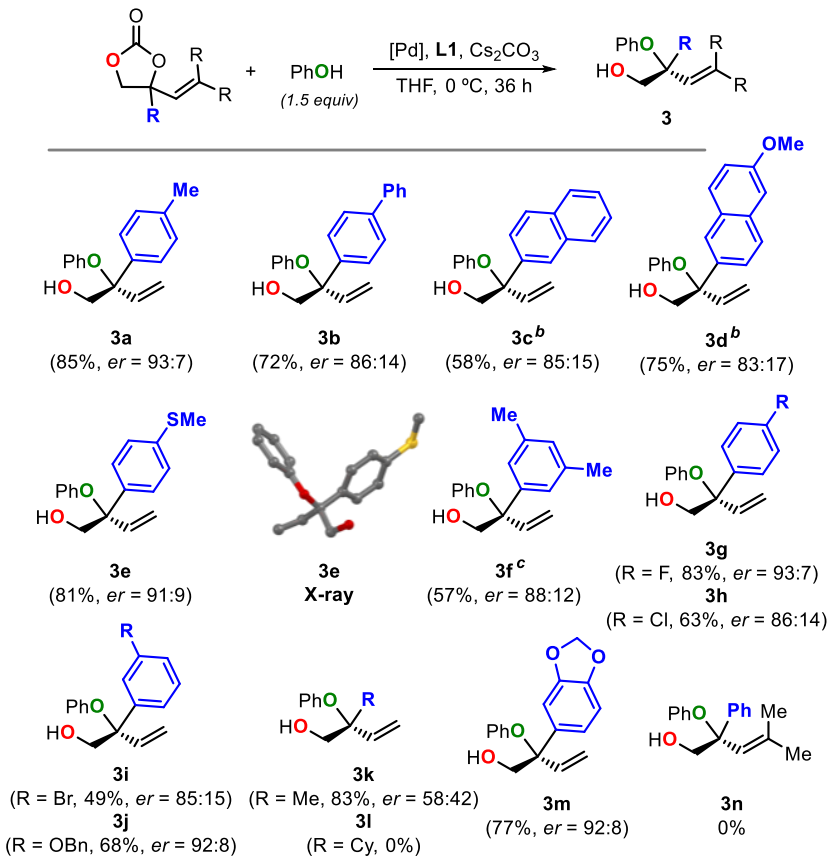

${ }^{a}$ Reaction conditions unless stated otherwise: carbonate $(0.20$ mmol), phenol (1.5 equiv), THF $(0.30 \mathrm{~mL}), \mathrm{Pd}_{2}(\mathrm{dba})_{3} \cdot \mathrm{CHCl}_{3}(2$ $\mathrm{mol} \%), \mathbf{L 1}(8 \mathrm{~mol} \%), \mathrm{Cs}_{2} \mathrm{CO}_{3}$ ( 3 equiv), $0{ }^{\circ} \mathrm{C}, 36 \mathrm{~h}$. Isolated yields are reported. ${ }^{b} 60 \mathrm{~h}$. ${ }^{c}$ Using $0.20 \mathrm{~mL}$ of THF.

Various substituted phenols proved to be suitable reaction partners to produce a range of allylic tertiary aryl ethers 2 (Scheme 3) in good yields and appreciable enantioinduction (generally er >90:10). Various para-substitutions on the phenol reagents including electron -withdrawing and -donating groups were endorsed, and meta- $(\mathbf{2 i}-\mathbf{2} \mathbf{k}, \mathbf{2 m}, \mathbf{2 n})$ and ortho-substituted phenols (2l, 2o) also showed good reactivity. It is worth noting that the introduction of two vinyl fragments in the aryl ether product is feasible as exemplified by the successful isolation of product 2o; this kind of product has potential in the synthesis of highly functionalized enantioenriched chromanes through olefin metathesis reactions. ${ }^{14}$

In order to further amplify the scope of the reaction, we then systematically varied the cyclic carbonates (Scheme 4 ) producing allylic aryl ethers 3 . Various aromatic substituents in the vinyl cyclic carbonate, including those having para- or meta-substitutions, were tolerated. The sulfur-containing substrate allowed to produce compound $\mathbf{3 e}$ without noticeable deactivation of the palladium catalyst (see also product $\mathbf{2 h}$ ). ${ }^{15}$ The aryl ether with bulky naphthyl group (3c, 3d) could be obtained through requiring longer reaction times. The methyl-substituted cyclic carbonate also proved to be reactive albeit with lower enantioselectivity (3k), while the bulky cyclohexyl-substituted carbonate showed no reactivity. The installation of a heterocycle in the aryl ether was feasible (3m), ${ }^{16}$ whereas attempts to install substituents on the vinyl group failed (3n). The absolute configuration of these tertiary aryl ethers $(S)$ was deduced by the Xray diffraction of the product $3 \mathbf{e}$ (Scheme 4 ).
Scheme 5. (Z)-Stereoselective Formation of the Linear Allylic Aryl Ethers $4^{a}$

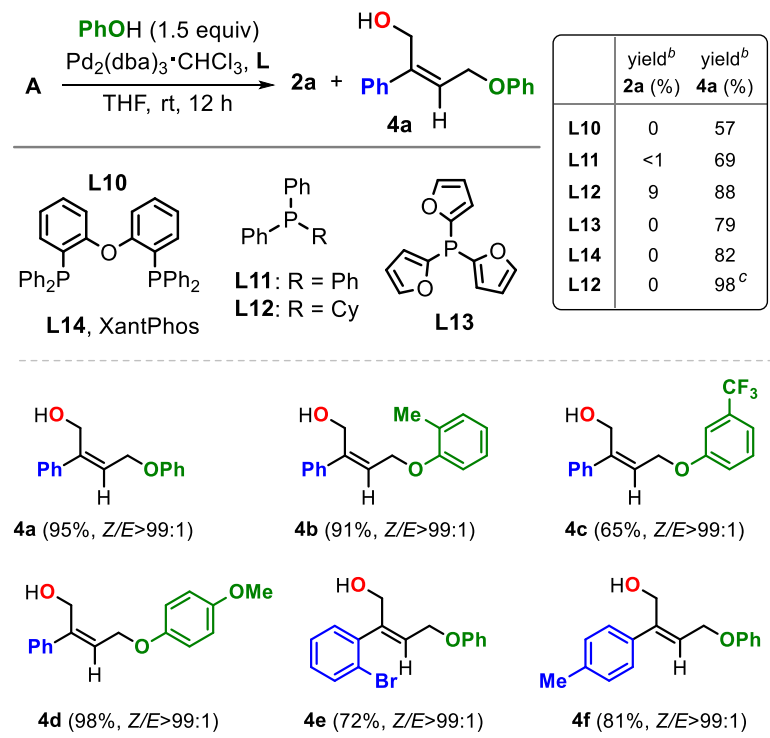

${ }^{a}$ Reaction conditions for the optimization toward linear aryl ether 4a: carbonate A $(0.20 \mathrm{mmol})$, phenol (1.5 equiv), THF $(0.20 \mathrm{~mL})$, $\mathrm{Pd}_{2}(\mathrm{dba})_{3} \cdot \mathrm{CHCl}_{3}(2 \mathrm{~mol} \%), \mathbf{L}(4 \mathrm{~mol} \%$ for $\mathbf{L 1 0}$ and $\mathbf{L 1 4} ; 8 \mathrm{~mol}$ $\%$ for L11-L13), rt, 12 h. ${ }^{b}$ Determined by ${ }^{1} \mathrm{H}$ NMR. ${ }^{c} \mathrm{Cs}_{2} \mathrm{CO}_{3}(3$ equiv) was added. Reaction conditions for $\mathbf{4 a - 4 f}$ : carbonate $(0.20$ $\mathrm{mmol})$, phenol (1.5 equiv), THF $(0.20 \mathrm{~mL}), \mathrm{Pd}_{2}\left(\mathrm{dba}_{3} \cdot \mathrm{CHCl}_{3}(2\right.$ mol \%), L12 (8 mol ), $\mathrm{Cs}_{2} \mathrm{CO}_{3}$ (3 equiv), rt, $12 \mathrm{~h}$. Isolated yields are reported.

Encouraged by our previous success in $(Z)$-stereoselective synthesis of linear allylic amines, ${ }^{9 a}$ we also probed the regioand stereoselective synthesis of highly functionalized linear allylic aryl ethers through a six-membered palladacyclic intermediate $^{9 \mathrm{a}}$ in the presence of suitable ligand. We first chose the reaction of phenol and cyclic carbonate $\mathbf{A}$ in THF at rt as a model reaction (Scheme 5). The use of $\mathbf{L 1 0}$ led to an appreciable yield of the linear product $\mathbf{4 a}(57 \%)$ while the branched product $\mathbf{2 a}$ was not observed (Table in Scheme 5). Further screening of ligands (L11-L14) suggested that $\mathbf{L 1 2}$ is the best ligand for the selective formation of linear allylic aryl ether $\mathbf{4 a}$ ( $88 \%$ yield). In contrast, only a small amount of the branched product $\mathbf{2 a}$ $(<9 \%)$ was observed suggesting that a judicious choice of the ligand is crucial to control the regioselectivity. Interestingly, the formation of branched product was further suppressed by the addition of $\mathrm{Cs}_{2} \mathrm{CO}_{3}$ and the yield of the linear product was improved to $98 \%$ indicating a subtle role of $\mathrm{Cs}_{2} \mathrm{CO}_{3}$ in this ligandgoverned process. ${ }^{17}$ It is worth noting that the use of ligands L10-L14 gave rise to product $\mathbf{4 a}$ with excellent stereoselectivity $(Z / E>99: 1)$, while the stereoselectivity in linear allylic amine formation strongly depended on the ligand utilized indicating the different reactivity of anilines and phenols. ${ }^{9 a}$ With the conditions optimized, the formation of linear allylic aryl ethers 4b-f was then investigated (Scheme 5) and showed in all cases good yields and excellent stereoselectivity. The ( $Z$ )-configuration of all the linear products was supported by ${ }^{1} \mathrm{H}$-selective 1D NOESY NMR analysis (see SI for details).

In summary, we here present a general method for the synthesis of otherwise synthetically challenging enantioenriched tertiary allylic aryl ethers through Pd-catalyzed decarboxylative 
reaction of vinyl cyclic carbonate and phenol type nucleophiles. The addition of $\mathrm{Cs}_{2} \mathrm{CO}_{3}$ proved to be crucial toward the formation of sterically hindered branched products. A judicious choice of the ligand switches the regioselectivity toward the $(Z)$ stereoselective formation of highly functionalized linear products. This mild protocol is characterized by a fair scope in reaction partners, overall good yields and appreciable enantio-induction.

\section{ASSOCIATED CONTENT}

\section{Supporting Information}

The Supporting Information is available free of charge on the ACS Publications website at DOI: xxx.

Experimental details and spectra for new products (PDF), $\mathrm{X}$-ray data for compound $\mathbf{3 e}(\mathrm{CIF})$

\section{AUTHOR INFORMATION}

\section{Corresponding Author}

*akleij@iciq.es

\section{Author Contributions}

\$These authors contributed equally to this work.

ORCID

Wusheng Guo: 0000-0001-5259-3600

Arjan W. Kleij: 0000-0002-7402-4764

Notes

The authors declare no competing financial interest.

\section{ACKNOWLEDGMENT}

We thank the Cerca program/Generalitat de Catalunya, ICREA, and the Spanish Ministerio de Economía y Competitividad (MINECO) through projects CTQ-2014-60419-R, and the Severo Ochoa Excellence Accreditation 2014-2018 through project SEV2013-0319. We acknowledge the analytical assistance (HPLC) from the CTAE unit from ICIQ. J.X thanks the CSC (201606200061) for a predoctoral fellowship.

\section{REFERENCES}

(1) For total synthesis of Ustiloxin D using an allylic tertiary aryl ether as intermediate: Sawayama, A. M.; Tanaka, H.; Wandless, T. J. J. Org. Chem. 2004, 69, 8810.

(2) (a) Trost, B. M.; F. D. Toste, J. Am. Chem. Soc. 1998, 120, 9074. (b) Trost, B. M.; Shen, H. C.; Dong, L.; Surivet, J.-P.; Sylvain, C. J. Am. Chem. Soc. 2004, 126, 11966. (c) Trost, B. M.; Shen, H. C.; Dong, L.; Surivet, J.-P. J. Am. Chem. Soc. 2003, 125, 9276. (d) Trost, B. M.; Asakawa, N. Synthesis 1999, 1491. (e) Trost, B. M. J. Org. Chem. 2004, 69, 5813.

(3) The enantioenriched derivatives of tertiary (allylic) aryl ethers are frequently encountered in pharmaceuticals or used as important building blocks in synthesis, see: (a) Trost, B. M.; Crawley, M. L. Chem. Rev. 2003, 103, 2921. Original contributions: (b) Cao, B.; Park, H.; Joullié, M. M. J. Am. Chem. Soc. 2002, 124, 520. (c) Tanaka, H.; Sawayama, A. M.; Wandless, T. J. J. Am. Chem. Soc. 2003, 125, 6864. (d) Mizuguchi, E.; Achiwa, K. Chem. Pharm. Bull. 1997, 45, 1209. (e) Pochetti, G.; Mitro, N.; Lavecchia, A.; Gilardi, F.; Besker, N.; Scotti, E.; Aschi, M.; Re, N.; Fracchiolla, G.; Laghezza, A.; Tortorella, P.; Montanari, R.; Novellino, E.; Mazza, F.; Crestani, M.; Loiodice, F. J. Med. Chem. 2010, 53, 4354.

(4) For the asymmetric synthesis of secondary allylic aryl ethers and related chemistry, see for example: (a) Trost, B. M.; Toste, F. D. J. Am.
Chem. Soc. 2000, 122, 11262. (b) Trost, B. M.; Tang, W. J. Am. Chem. Soc. 2002, 124, 14542. (c) Onitsuka, K.; Okuda, H.; Sasai, H. Adv. Synth. Catal. 2008, 47, 1454. (d) Kirsch, S. F.; Overman, L. E.; N. S. White, Org. Lett. 2007, 9, 911. (e) Kim, D.; Reddy, S.; Singh, O. V.; Lee, J. S.; Kong, S. B.; Han, H. Org. Lett. 2013, 15, 512. (f) Trivedi, R.; Tunge, J. A. Org. Lett. 2009, 11, 5650. (g) Austeri, M.; Linder, D.; Lacour, J. Chem. Eur. J. 2008, 14, 5737. (h) Olson, A. C.; Overman, L. E.; Sneddon, H. F.; Ziller, J. W. Adv. Synth. Catal. 2009, 351, 3186. (i) Trost, B. M.; Toste, F. D. J. Am. Chem. Soc. 1998, 120, 815. (j) Austeri, M.; Linder, D.; Lacour, J. Adv. Synth. Catal. 2010, 352, 3339. (k) Trost, B. M.; Gunzner, J. L.; Dirat, O.; Rhee, Y. H. J. Am. Chem. Soc. 2002, 124, 10396. (1) Trost, B. M.; Crawley, M. L. J. Am. Chem. Soc. 2002, 124,9328 .

(5) To the best of our knowledge, there is only one known example of the asymmetric synthesis of tertiary allylic aryl ether through phenol nucleophilic substitution. However, this protocol has quite limited scope, see ref 2a. Controlling the regioselectivity in allylic substitution with phenols is challenging, see: (a) Goux, C.; Massacret, M.; Lhoste, P.; Sinou, D. Organometallics 1995, 14, 4585. (b) Trost, B. M.; Toste, F. D. J. Am. Chem. Soc. 1999, 121, 4545.

(6) For asymmetric synthesis of allylic tertiary alkyl ethers through allylic substitution with alcohol nucleophiles: (a) Trost, B. M.; McEachern, E. J.; Toste, F. Dean, J. Am. Chem. Soc. 1998, 120, 12702. (b) B. M. Trost, B. S. Brown, E. J. McEachern, O. Kuhn, Chem. Eur. J. 2003, 9, 4442. (c) Khan, A.; Khan, S.; Khan, I.; Zhao, C.; Mao, Y.; Chen, Y.; Zhang, Y. J. J. Am. Chem. Soc. 2017, 139, 10733.

(7) Continuous endeavors have been devoted to develop new methods for the asymmetric synthesis of tertiary aryl ethers, please see for example: (a) Forbeck, E. M.; Evans, C. D.; Gilleran, J. A.; Li, P.; Joullié, M. M. J. Am. Chem. Soc. 2007, 129, 14463. (b) Woiwode, T. F.; Rose, C.; Wandless, T. J. J. Org. Chem. 1998, 63, 9594. (c) Shibatomi, K.; Kotozaki, M.; Sasaki, N.; Fujisawa, I.; Iwasa, S. Chem. Eur. J. 2015, 21, 14095. (d) Li, P.; Forbeck, E. M.; Evans, C. D.; Joullié, M. M. Org. Lett. 2006, 8, 5105. (e) Woiwode, T. F.; Rose, C.; Wandless, T. J. J. Org. Chem. 1998, 63, 9594.

(8) Seminal work using vinyl cyclic carbonates in synthetic chemistry: Bando, T.; Harayama, H.; Fukazawa, Y.; Shiro, M.; Fugami, K.; Tanaka, S.; Tamaru, Y. J. Org. Chem. 1994, 59, 1465.

(9) Selected recent examples including contributions from our research group: (a) Guo, W.; Martínez-Rodríguez, L.; Kuniyil, R.; Martin, E.; Escudero-Adán, E. C.; Maseras, F.; Kleij, A. W. J. Am. Chem. Soc. 2016, 138, 11970. (b) Guo, W.; Martínez-Rodríguez, L.; Martín, E.; Escudero-Adán, E. C.; Kleij, A. W. Angew. Chem. Int. Ed. 2016, 55, 11037. (c) Khan, A.; Zheng, R.; Kan, Y.; Ye, J.; Xing, J.; Zhang, Y. J. Angew. Chem. Int. Ed. 2014, 53, 6439. (d) Ohmatsu, K.; Imagawa, N.; Ooi, T. Nat. Chem. 2014, 6, 47. (e) Wang, H.; Lorion, M. M.; Ackermann, L. ACS Catal. 2017, 7, 3430. (f) Gómez, J. E.; Guo, W.; Kleij, A. W. Org. Lett. 2016, 18, 6042.

(10) Cai, A.; Guo, W.; Martínez-Rodríguez, L.; Kleij, A. W. J. Am. Chem. Soc. 2016, 138, 14194.

(11) (a) Kumar, N.; Leray, I.; Depauw, A. Coord. Chem. Rev. 2016, 310, 1. (b) Awual, M. R.; Yaita, T.; Miyazaki, Y.; Matsumura, D.; Shiwaku, H.; Taguchi, T. Sci. Rep. 2016, 19937.

(12) Hydrogen bond assistance should also be considered, please refer to ref $9 \mathrm{a}$ and ref 10 .

(13) Alkali metal cations have strong affinity for oxygen donors, see for example ref 11 .

(14) Enantioenriched chromanes are important fragments in many drugs and natural products such as Vitamin E, Clusifoliol, Siccanin and Calanolide A, see ref 2.

(15) The S-containing substrates have the potential to poison the Pdcatalyst and typically require higher reaction temperatures, see ref $9 \mathrm{f}$.

(16) Enantioenriched compounds with 1,3-benzodioxole fragments are of interest in pharmaceutical development: Bloom, J. D.; Dutia, M. D.; Johnson, B. D.; Wissner, A.; Burns, M. G.; Largis, E. E.; Dolan, J. A.; Claus, T. H. J. Med. Chem. 1992, 35, 3081.

(17) In the presence of $\mathbf{L 1 2}$, the likely formation of the more nucleophilic $\mathrm{CsOPh}$ species further facilitates catalytic turnover. 